\title{
Remarkable Funders: How Early-Late Backers and Mentors Affect Reward-Based Crowdfunding Campaigns
}

\author{
Francesco Gangi ${ }^{1}$, Lucia Michela Daniele ${ }^{1}$ \\ ${ }^{1}$ Department of Management, University of Campania “Luigi Vanvitelli”, Capua, Italy \\ Correspondence: Francesco Gangi, Department of Management, University of Campania, Capua, Italy.
}

Received: September 4, 2017

Accepted: September 26, 2017 Online Published: September 29, 2017

doi:10.5539/ibr.v10n11p58

URL: https://doi.org/10.5539/ibr.v10n11p58

\begin{abstract}
In recent years, the growth of the reward-based crowdfunding model has offered new opportunities to meet the funding requirements of start-ups. However, the achievement of the funding target is still a complex goal, given the existence of several information barriers between insiders (project proponents) and outsiders (backers) of a crowdfunding campaign. Within the framework of the information asymmetry and the theory of signals, this study aims to analyse the role of two kinds of previously un-investigated funders in determining the success of crowdfunding campaigns: early-late backers (who are placed at the beginning of the tail of the campaign) and mentors (who are represented by firms acting as more expert backers). The findings indicate that both types of funders are remarkably important for the success of a crowdfunding campaign.
\end{abstract}

Keywords: crowdfunding, information asymmetry, reward-based model, signalling theory

\section{Introduction}

In recent years, crowdfunding has emerged as a financing channel for a wide range of entrepreneurial initiatives, both for and not-for profit. The main feature of this unconventional model of raising capital is the use of Internet platforms that allow proponents of a project (creators) to reach an indefinite set (the crowd) of potential funders (backers) (Note 1). The diffusion of crowdfunding is confirmed by the numbers: worldwide, there are more than 1,200 portals, with the capital collection exceeding 16.2 billion dollars in 2014, which represents a $160 \%$ growth from 2013 (Massolution, 2015). In parallel with this growth, scientific interest in the crowdfunding phenomenon has significantly increased, including the search for a taxonomy (Griffin, 2012; Kaartemo, 2017). With reference to the reward-based model, which represents the focus of this paper, crowdfunding can be defined as an open call for providing financial resources in exchange for future products or some form of rewards (Belleflamme, Lambert, \& Schwienbacher, 2014).

Since the evidence suggests that the legitimacy of a project to be funded is not easy to obtain during crowdfunding (Frydrych, Bock, Kinder, \& Koeck, 2014), one of the most salient research topics is the study of determinants of a successful campaign, which is defined as an initiative that reaches its funding target. In this regard, the literature has provided some theoretical and empirical evidence, but the topic is still far from being fully explored. Further investigations on why some projects succeed while others fail are rooted in a well-established conceptual framework represented by the information asymmetry (Akerlof, 1970) and the theory of signals (Spence, 1973).

The crowdfunding market shows a mix of specific elements that may exacerbate the distorting effects caused by the informational distance that normally exists between the insiders (creators or proponents) and outsiders (backers) of a project. Some of these elements are the virtual environment of transactions, the absence of personal interaction, the lack of formal procedures for the assessment of project quality, and the participation of backers without expertise at the individual level. All these distinguishing features present the question of which factors can mitigate the information barriers that may hinder the achievement of the funding target. The present paper aims at contributing to fill this knowledge gap. In particular, assuming that the crowd is not a monolithic entity, this study focuses on the 'certification' function of some kinds of funders who have not been investigated earlier, such as the backers placed at the beginning of the tail of a crowdfunding campaign and the firms that act as mentors of a project. The theoretical basis here is the social information embedded in others' funding decisions (Kuppuswamy and Bayus, 2015), that may mitigate the distortions of the information asymmetry. 
Similar to what happens in online auctions (Ockenfels \& Roth, 2006), in the case of crowdfunding campaigns too, a significant number of backers are distributed closer to the deadline of the time window of a crowdfunding campaign (Kuppuswamy \& Bayus, 2015). Therefore, unlike previous literature that has focused on the effect of early backers intervening at the start of the campaign (Colombo, Franzoni, \& Rossi - Lamastra, 2014), this paper studies the impact of the early-late backers who are placed at the beginning of the tail of the fundraising process on crowdfunding platforms.

In relation to the standing of potential funders, the focus of this study is also on the impact of firms that act as backers with more expertise or representative backers. The latter are renowned companies that exercise a mentoring function toward the feasibility of an initiative. The theoretical framework is the endorsement effect of prominent third parties (Stuart, Ha, \& Ralph., 1999) that may mitigate information barriers the backers in general have to face due to a widespread lack of expertise at the individual level.

The hypotheses are tested through data obtained from Produzioni dal Basso and Eppela, which are the main Italian platforms. This investigation is also an opportunity to analyse reward-based crowdfunding in a very little investigated country compared to other socio-economic systems such as the Anglo-Saxon contexts (Bouaiss, Maque, \& Mèric, 2016). We use a sample of 578 campaigns launched in Italy between 2013 and 2015. The econometric models fully support the assumptions of the study about the positive impact that early-late backers and companies acting as mentors have on the probability of a campaign reaching the funding target.

The remainder of this paper is arranged as follows. The next section presents the theoretical background and the hypotheses. The third section addresses the methodology, while the fourth section presents and discusses the empirical results of the survey. The final section contains the conclusions of the study and indications for future research directions.

\section{Theoretical Background and Hypotheses}

\subsection{Information Asymmetry in Reward-Based Crowdfunding}

As theorised by Akerlof (1970), the information asymmetry between actors of an exchange process may degenerate into distorting effects, such as the adverse selection phenomenon, that enhance the feeling of uncertainty and risk underlying the transaction. With regard to this problem, the signalling theory (Spence, 1973) analysed the mitigating impact of information cues. In particular, the theory of signals has found extensive application in the studies on venture capital (Baum \& Silverman, 2004; Gompers, 1996; Lee \& Wahal, 2004). However, in the reward-based crowdfunding market, information asymmetries and signals assume specific features that are connected to the mechanisms of this unconventional financial mode. In fact, similar to other on-line markets, the condition of asymmetric information between insiders and outsiders is fuelled by the virtual environment in which a new initiative is presented and the financing decision is taken. In addition, the use of internet platforms not only modifies the storytelling of a project (Frydrych et al., 2014), but also affects the screening process, which must do without any personal dialogue between founder and funder (Agrawal, Catalini, \& Goldfarb, 2015). Moreover, as an electronic market, reward-based crowdfunding may be associated with an increase in fraud risk, as fictitious applicant profiles could be created and the disclosure of information may not be easily verifiable remotely. Therefore, compared to conventional forms of financing, the digital context and the physical disintermediation limit the assessment of quality and trustworthiness based on a more standardized mix of hard and soft information that is usually obtainable through financial statements, official documents and repeated personal interactions (Petersen, 2004; Stein, 2002).

The use of the internet has further contrasting implications. In particular, the economic benefit derived from the reduction of the geographical distance between proponents and funders is counterbalanced by lower backer protection due to potential conflicts existing between different jurisdictions (Tomboc, 2013). Moreover, from the perspective of the proponent, additional risks may arise due to the absence of confidentiality agreements or other instruments that can safeguard the creator's rights. In addition, the lack of prior agreements may discourage the founder from disclosing sensitive details of the new initiative, which might have a detrimental effect on the screening process. Therefore, while the poor structuring of crowdfunding and virtual media can help its diffusion, they may be also a disadvantage with regard to the mitigation of information asymmetry.

Despite the frequent parallelism drawn between crowdfunding and the venture capital market (Cordova, Dolci, \& Gianfrate, 2015; Courtney, Dutta, \& Li, 2017; Mollick, 2014), reward-based crowdfunding has a significantly different approach that sharpens the informative distance between founders and funders. There is not a formal due diligence, the financing method by stages is unsuitable for one time projects, and there are no governance agreements due to the frequent absence of legally recognized companies behind the new venture. 
In addition, backers generally have limited technical knowledge regarding a project, and therefore, they do not perform the same certification function that literature attributes to venture capitalists (Gompers, 1995; Megginson \& Weiss, 1991).

As stated by Kim and Viswanathan (2016), while players in the formal venture capital market require a mix of money and expertise for the evaluation and management of risks, reward-based crowdfunding unbinds these two resources and allows funders without the necessary competencies to be part of the financing campaign (Agrawal, Catalini, \& Goldfarb, 2014; Ahlers, Cumming, Günther, \& Schweizer, 2015). It is a democratization phenomenon that broadens the participation of potential backers, but at the same time, it may exacerbate the information asymmetry condition that advocates can experience at the act to select and finance an initiative which has attracted their interest.

All the studies published in the literature so far imply that less sophisticated and poorly informed funders could benefit from signals of quality and trustworthiness that are not directly observable. Therefore, it is important to identify factors that may act as informational cues and counterbalance the risks connected to the information gap between creators and backers. The relevance of signals is confirmed by earlier studies on the proxies of project quality (Courtney et al., 2017; Cumming, Leboeuf, \& Schwienbacher, 2014; Kunz, Bretschneider, Erler, \& Leimeister, 2017; Mollick, 2014;), on the social capital (Nahapiet and Goshal, 1998; Greve and Salaff, 2003) and on the digital networks (Mollick, 2014; Colombo et al., 2014; Cumming et al., 2015; Thies and Wessel, 2014; Kunz et al., 2017; Kang, Jiang, \& Tan, 2017). The common denominator of these research paths is the identification of drivers that can mitigate the information asymmetry affecting the crowdfunding market. From this perspective, the social information embodied in others' funding decisions (Kuppuswamy \& Bayus, 2015) may be an additional resource which compensates for the lack of direct observation or limited personal capability to assess the feasibility of a crowdfunding campaign. Therefore, the focus of this study is on two different kinds of backers who have not yet been investigated, but are potentially important for reaching the funding target: (1) early-late backers who give a signal to advocates during the tail of the campaign (the deadline effect) and (2) renowned firms (the endorsement effect) that play the role of mentors of a project (see Fig. 1).

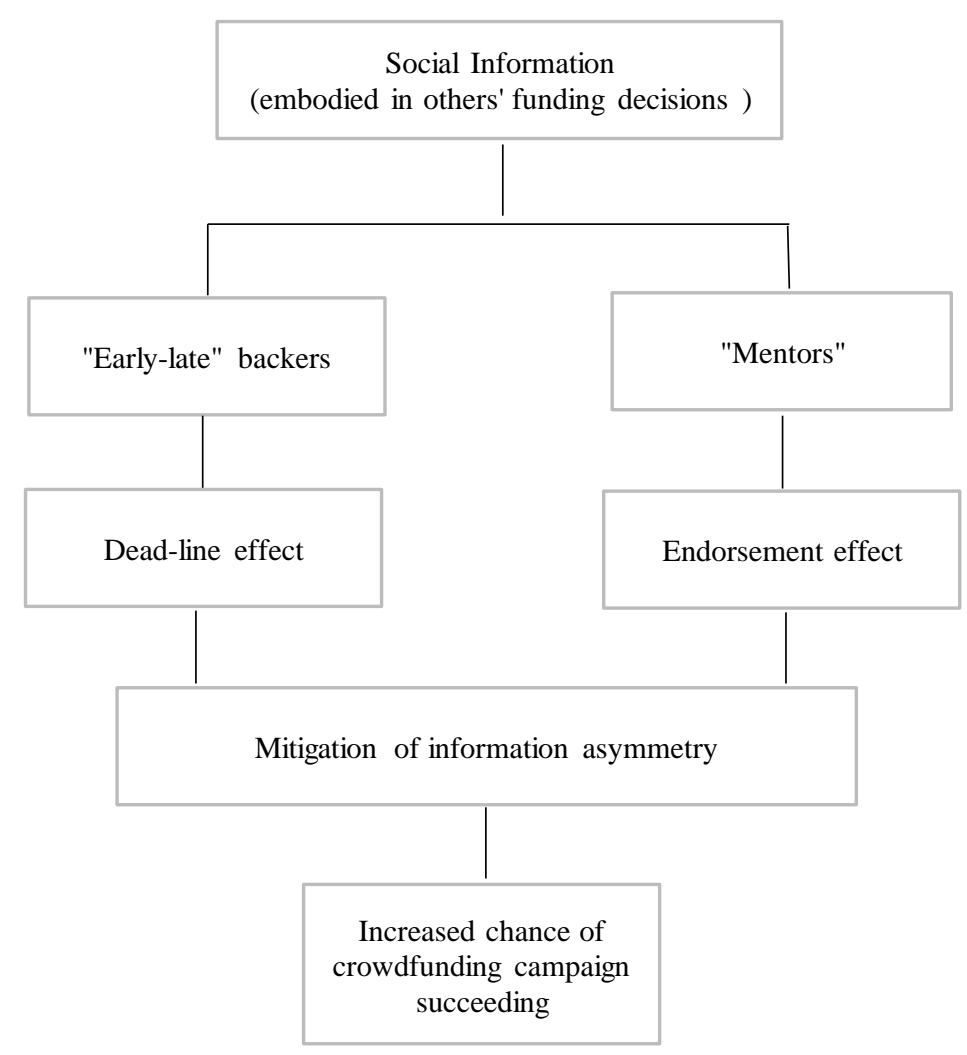

Figure 1. Conceptual framework 


\subsection{Impact of 'Early-Late' Backers}

Mimicking the behaviour of others, although not necessarily the best decision, can be considered as rational behaviour in the presence of information asymmetries that separate the potential willingness to act from the actual action. Considering that "one buyer's behaviour affects another buyer's expected utility" (Hu, Li, \& Shi, 2015, pag.355), the basis of this approach may lie in economic convenience. That is, since participation in a crowdfunding campaign is at the least a time-consuming decision (Note 2), the option to fund an initiative already supported by others could be efficient due to the fact that the campaign has a higher probability of success. That is, pledging money to a project that seems likely to succeed is more appealing than pledging money to a campaign that appears likely to fail. In fact, according to the reinforcement model (Cordova et al., 2015), the higher the popularity of a project among the crowd, the higher are its chances of reaching the funding goal. It has been observed that backers are not homogenously distributed along the time window of a campaign. In particular, a relevant portion tend to be placed at the end of the time window (Kuppuswamy \& Bayus, 2015, 2017). This behavioural model is explained by the deadline effect, and it is very thoroughly described within the context of the games theory and the field of social psychology. In game theory research, experimental analysis shows that agreement between parties is frequently achieved in the terminal stages of a bargaining process (Gneezy, Kapteyn, \& Potters, 2003; Roth, Murnighan, \& Schoumaker, 1988). In social psychology research, delaying a final decision or an action has been shown to be a familiar and widespread behaviour among people (Ariely \& Wertenbroch, 2002). This behaviour tends to diminish significantly in the proximity of an official deadline, while the effect produced by a self-imposed deadline seems to be less effective. All this evidence strengthens the belief about the existence of a deadline effect, especially if the individual cannot change the rules of the deadline, as in the case of the procedures imposed by crowdfunding platforms or some on-lines auctions (Ariely \& Simonson, 2003; Ariely, Ockenfels, \& Roth, 2003; Ockenfels \& Roth, 2006).

If in a given informative context, waiting for the deadline before deciding may seem like a rational strategy, according to social psychology (Ariely and Wertenbroch, 2002), with the expiry of a deadline, the balance between benefits and costs of bystander behaviour tends to change. This occurs especially when the deadline for taking the decision can no longer be postponed, and when the lack of individual action near the deadline is associated with the risk of losing the last opportunity to facilitate a positive outcome of a given initiative. From this perspective, in the reward-based crowdfunding market, late backers that are placed along the tail of the harvesting phase can be determinants of the success of a campaign. More specifically, in terms of signalling, we refer to the advocates that act at the beginning of the tail of the campaign and that conventionally may be called early-late backers. These advocates can trigger the final effort for a campaign to succeed. The transmission mechanisms of their behaviours near the expiration date can be compared to those of the initial backers (Colombo et al., 2014), such as observational learning (Bikhchandani, Hirshleifer, \& Welch, 1998) and word of mouth (Arndt, 1967) which concur to mitigate the absence of better and direct information. In the case of both mechanisms, the funders positioned in proximity of the deadline of the campaign derive information from merely observing the behaviour of others. Therefore, the early-late backers consolidate the signalling and financial efforts of earlier funders, as well as launch the final sprint of the later backers, thereby increasing the chances of the project reaching the financing target. Based on this information, the first hypothesis is formulated as follows:

H1: Early-late backers have a positive impact on the likelihood of a reward-based crowdfunding campaign succeeding.

\subsection{Impact of a Project Mentor}

Studies on early-stage financing have highlighted that the certification function of venture capitalists is not independent of their standing (Gompers 1996; Gompers \& Lerner, 1997; Lee \& Wahal, 2004). That is, the weight of a signalling effect in the capital market increases with increase in the reputation and experience of funders. These findings can be applied to understand the mechanics of reward-based crowdfunding. In particular, this unconventional market may be segmented on the supply side, not only according to the entry time of backers, but also according to their reputation and expertise (Kim \& Viswanathan, 2016).

The participation of more competent and renowned funders can promote the success of the crowdfunding campaign, both through their financial contribution and the certification of the new initiative. Moreover, hesitant and less experienced backers have the opportunity to exploit the information that arises from the participation of well-known supporters (Kim \& Viswanathan, 2016). This phenomenon can be compared to the endorsement effect of prominent third parties (Stuart et al., 1999), whose participation can provide a signal of further credibility to a crowdfunding campaign (Cordova et al., 2015; Courtney et al., 2017). 
It is not always easy to identify the features of a supporter. While within conventional financial markets the endorsement effect can be more easily attributable to qualified merchant banks or venture capitalists with a broad track record, in the crowdfunding market, it is more complex due to the high level of anonymity and variance in the composition of the crowd. For this reason, the endorsement effect can be more easily attributable to the presence of organizations represented by companies that are already operating in the same sector of the new goods or services presented on the platform, or to well-known firms that pursue social objectives. A backer with these characteristics may assume the role of mentor of a project that can contribute to the success of the campaign through the mix of financial resources and expertise. In fact, both these transactional resources co-exist in the case of mentors, without distorting the functioning of a reward-based crowdfunding market.

Therefore, the second hypothesis is formulated as follows:

H2: The participation of a mentor has a positive impact on the likelihood of a reward-based crowdfunding campaign succeeding.

\section{Method}

\subsection{Data Collection}

This study obtained data on reward-based crowdfunding from the two main Italian platforms: Produzioni dal Basso and Eppela. The choice to analyse the Italian market was based on several factors. First, it is a less investigated country. Second, there is a digital divide between Italy and other advanced European nations (European Commission, DESI 2016). Third, crowdfunding has experienced relevant growth in the Italian context. In particular, with a collection of 56.8 million Euros (Univ. Cattolica and TIM, 2016), Italy represented 10\% of the European crowdfunding market at the end of 2015. The average size of project funds is around 5000 Euro, and the reward-based model represents $13 \%$ of the Italian crowdfunding market. Moreover, reward-based crowdfunding has seen a significant increase in terms of platforms ( 90 are currently active) and funds raised (89\%). At the same time, Italy shows (We are social, 2016) a web penetration index equal to $58 \%$ as opposed to the European average of $68 \%$, and a lower social penetration index $(46 \%)$ than that in the most advanced and investigated countries such as the US (58\%) and UK (59\%).

Internet platforms represent one of major actors of any crowdfunding market. The literature has mainly focused on data gathered from two leading platforms in the US: Indiegogo and Kickstarter. However, the quantity and quality of data disclosed by platforms are not homogeneous, and this limits the generalizability of prior findings. A higher degree of information, about both the creators and backers, is a main feature of Kickstarter and Indiegogo, but these attributes are not universal among internet platforms (see Appendix A). The existence of such differences is an additional justification for advancing the state of knowledge about crowdfunding in a technical context such as Italy. In May 2016, Eppela and Produzioni dal Basso accounted for $92 \%$ of the total successful projects on hybrid platforms (reward and donation-based) and 60\% of the funds raised in Italy (Starteed, 2016). Both of them are generalist platforms, since they host projects from different sectors.

\subsection{Variables and Models}

The present study covers all the reward-based crowdfunding campaigns on Produzioni dal Basso and Eppela that ended between 2013 and 2015. However, 238 projects were dropped during the sampling process because it was not possible to trace the amount of capital required. Therefore, the final sample consists of 578 campaigns: 391 (68\%) were extracted from the Eppela platform, while the remaining 187 (32\%) were from Produzioni dal Basso. Data for each project were gathered directly from the platforms.

The empirical analysis applied here is both descriptive and inferential. In particular, this paper adopts logistic models following a forward stepwise regression approach in order to identify the statistical significance of variables and models. In accordance with previous studies (Colombo et al., 2014; Cordova et al., 2015; Kunz et al., 2017; Mollick, 2014), the dependent variable was a dummy (Success), which was assigned a value of 1 if the campaign was successful (that is, pledges covered at least $100 \%$ of the funding target) and 0 otherwise (that is, pledges covered less than $100 \%$ of the funding target).

Since the platforms make visible the necessary information, in order to test the first hypotheses (H1), in all the econometric models, this study adopts a variable (Early_Late_Backers) which measures the number of backers conventionally identified as advocates whose participation occurs in a time window equivalent to one-sixth of the tail of the campaign (Note 3). In particular, the platforms show a list of those who are indicated as late backers, in addition to the date of their intervention. The tail starts with the first of the late backers reported on the crowdfunding platforms. The tail length shows a time interval that on average equals 8 days, with a maximum of 52 days. 
For testing of the second hypothesis (H2), the logistic models include a dummy variable (Mentor) that is assigned a value of 1 if a project received the support of a company that assumed a mentoring and funding function and 0 otherwise.

The analysis adopts several control variables that cover a wide range of information about project characteristics and digital interaction with backers. These variables are consistent with previous studies that highlighted the effects of project size, the average contribution by backers, the impact of proxies of project quality, and the influence of relational capital mediated by social networks (Colombo et al., 2014; Cordova et al., 2015; Kunz et al., 2017; Mollick, 2014). The following control variables were used:

Log_Funding Target: This is a logarithmic measure of the funding target required by the proponent.

Log_Funding per backer: This is the logarithmic value of the mean contribution of backers.

Photo: This is a dummy variable that is assigned a value of 1 if the project presentation includes at least one photo, and is assigned a value of 0 otherwise.

Video: This is a dummy variable that is assigned a value of 1 if the project presentation includes at least one video and 0 otherwise.

Updates and Comments: These variables measure the number of updates and comments on a project, respectively, during the campaign.

$F B \_$Page: This is a dummy variable that is assigned a value of 1 if the campaign has a Facebook page associated with the project and 0 otherwise.

$T W \_$Account: This is a dummy variable that is assigned a value of 1 if the project page includes a Twitter account dedicated to the initiative and 0 otherwise.

The logistic regressions include a project category control through eight dummy variables related to the sector classification proposed by the platforms (Note 4). In addition, to control for the digital divide in the Italian context, the models include a variable which measures the social network penetration rate in Italy by year (SNindex) within the time window analysed for each project.

The regression models are formalized as follows:

Model 1: Success $=\beta_{1}$ Early_Late_Backers $+\beta_{2}$ Mentor $+\beta_{3} \log \_$FT $+\beta_{4} \log \_$Fund $\_$back $+\beta_{5}$ SN_index + $\beta_{6}$ Sector.

Model 2: Success $=\beta_{1}$ Early_Late_Backers $+\beta_{2}$ Mentor $+\beta_{3} \log \_$FT $+\beta_{4} \log \_$Fund_back $+\beta_{5}$ Photo $+\beta_{6}$ Video + $\beta_{7}$ Updates $+\beta_{8} \mathrm{SN} \_$index $+\beta_{9}$ Sector.

Model 3: Success $=\beta_{1}$ Early_Late_Backers $+\beta_{2}$ Mentor $+\beta_{3}$ Log_FT $+\beta_{4}$ Log_Fund_back $+\beta_{5}$ Photo $+\beta_{6}$ Video + $\beta_{7}$ Updates $+\beta_{8}$ Comments $+\beta_{9} \mathrm{Fb}$ _page $+\beta_{10} \mathrm{Tw} \_$account $+\beta_{11} \mathrm{SN} \_$index $+\beta_{12}$ Sector.

Finally, through the application of the SPSS programme, the study adopts several goodness of fit measures for logistic regressions (overall percentage, Cox \& Snell R-square, Nagelkerke R-square, and the Hosmer-Lemeshow Test). All the measures indicate that the models adequately fit the data.

\section{Results}

\subsection{Descriptive Statistics}

Table 1 provides descriptive statistics related to both successful and failed campaigns. The first group consists of 454 initiatives, representing 79\% of the total campaigns included in our data. On average, the funding target of successful campaigns is slightly lower $(€ 5341,11)$ than the amount of capital that failed projects seek to raise ( $€$ $5855,24)$. On the contrary, the mean funding ratio, which represents the ratio of the final funding to the capital requested, is much higher in the successful group (1.09) than in the failed group (0.09). This evidence is consistent with prior descriptive analyses (Frydrych et al., 2014). In fact, successful projects tend to get over-funded, while unsuccessful campaigns fail by a wide margin. In other words, as stated by Mollick (2014), failures happen by large amounts, successes by small amounts. This feature of the reward-based crowdfunding market is confirmed by the percentage of the funding target achieved by the failed initiatives (see Fig. 2): 54\% of the unsuccessful projects did not exceed $10 \%$ of the amount requested, $35 \%$ collected between $11 \%$ and $30 \%$ of the amount requested, $7 \%$ collected between $31 \%$ and $50 \%$, and only $4 \%$ of the failed projects exceeded more than $50 \%$ of the initial capital requested. 


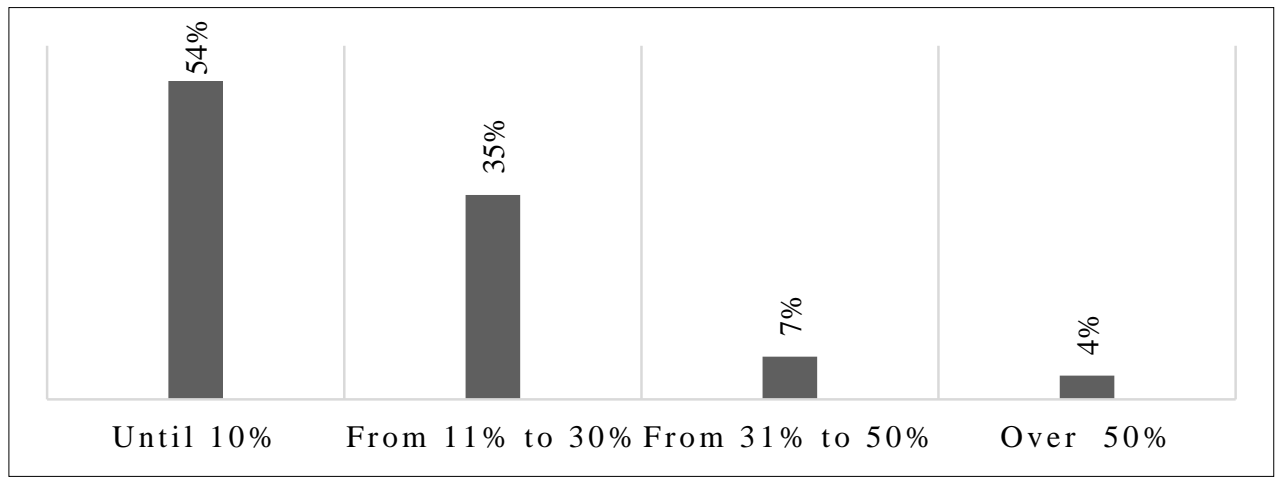

Figure 2. Percentage of requested funding received for failed projects

The distribution of the funding ratio between the successful and unsuccessful projects confirms the difficulty faced by a new initiative in being legitimized during a crowdfunding campaign. This trend finds additional support in the data on the backers. On average, successful projects had a higher number of advocates (78.15) than failed projects (17.48). Moreover, for projects that reached or overreached the funding target, the average contribution by backers was more than double $(€ 79,98)$ that of failed campaigns $(€ 34,03)$. Finally, by segmenting the crowd according to entry time and the standing of backers, the following differences were observed between successful and unsuccessful projects: (1) the mean incidence of early-late backers along the tail of the campaign was higher for successful projects (35\%) than failed initiatives (9\%), and (2) a higher percentage of successful campaigns than unsuccessful campaigns were backed by a mentor (16\% vs. $2 \%$ ). Therefore, the participation of a renowned firm seems to be a distinctive feature of initiatives that have reached at least the financial budget.

Table 1. Descriptive statistics

\begin{tabular}{lllll}
\hline Successful (N= 454) & Mean & St. Dev. & Min & Max \\
\hline Funding target & 5341.11 & 8935.75 & 350.00 & 100000.00 \\
Final funding & 6164.26 & 13732.56 & 350.00 & 238308.00 \\
Funding ratio & 1.09 & 0.11 & 1.00 & 2.38 \\
N. Backers & 78.15 & 240.00 & 2.00 & 4783.00 \\
Funding per backers & 70.98 & 22.64 & 44.48 & 280.00 \\
Early last backers/ Last backers & 0.35 & 0.23 & 0.00 & 0.90 \\
Mentor & 0.16 & 0.37 & 0.00 & 1.00 \\
\hline Failed (N= 124) & Mean & St. Dev. & Min & Max \\
\hline Funding target & 5855.24 & 4895.64 & 600.00 & 35000.00 \\
Final funding & 766,06 & 1255.88 & 5,00 & 10607.00 \\
Funding ratio & 0.09 & 0.05 & 0.01 & 0.31 \\
N. Backers & 17.48 & 17.43 & 1.00 & 105.00 \\
Funding per backers & 34.03 & 12.76 & 5.00 & 101.02 \\
Early last backers/ Last backers & 0.09 & 0.21 & 0.00 & 1.00 \\
Mentor & 0.02 & 0.15 & 0.00 & 1.00 \\
\hline
\end{tabular}

4.2 Multivariate Analysis

In this section, the study aims to provide econometric evidence that the specific backer categories under investigation, such as the early-late backers and the mentor, are significant determinants of successful reward-based crowdfunding campaigns. In the third model, which includes all the variables, the average VIF is 1.384, which is below the conventional threshold of 6 , and the maximum VIF is 2.334 , below the conventional threshold of 10 (McDonald \& Moffit, 1980). Moreover, all the values of the correlation matrix are sufficiently lower than the conventional threshold of 0.7 (Ratner, 2009). These findings indicate that multicollinearity is not an issue (Note 5). The findings of the regression analysis are reported in Table 3. First, as expected, the backers placed along the beginning of the tail of the campaign have a positive impact on the success of initiatives. That is, the higher the number of early-late backers, the more likely is the reward-based crowdfunding campaign to reach the funding target. This confirms the role of remarkable funders during a critical phase of the crowdfunding cycle represented by the approach of the expiration date of a campaign (deadline effect). Second, the presence of a company that supports a campaign is a positive predictor of successful crowdfunding initiatives. The participation of renowned companies functions not only as an additional financing contribution, but also as an 
endorsement of the new project. Therefore, transactional resources (Kim \& Viswanathan, 2016), represented by a mix of financial capital and know-how, allow these kinds of advocates to fuel the chances of success of a reward-based crowdfunding campaign.

Table 3. Logistic regression models

\begin{tabular}{|c|c|c|c|c|c|c|}
\hline \multirow{3}{*}{ Independent variables } & \multicolumn{6}{|c|}{ Dependent Variable: Success } \\
\hline & \multicolumn{2}{|c|}{ Model 1} & \multicolumn{2}{|c|}{ Model 2} & \multicolumn{2}{|c|}{ Model 3} \\
\hline & B coeff. & Wald & B coeff. & Wald & B coeff. & Wald \\
\hline Early_late_backers & $0.659 * * *$ & 47.204 & $0.719 * * *$ & 46.214 & $0.725 * * *$ & 45.907 \\
\hline Mentor & $4.410 * * *$ & 30.029 & $4.617 * * *$ & 31.615 & $4.618 * * *$ & 31.29 \\
\hline Log_FT & $3.924 * * *$ & 38.136 & $4.315^{* * *}$ & 40.223 & $4.268 * * *$ & 38.698 \\
\hline Log_Fund_back & $-3.811 * * *$ & 37.323 & $-4.017 * * *$ & 38.342 & $-4.0156 * * *$ & 38.058 \\
\hline Photo & & & $-1.464 * *$ & 9.864 & $-1.463 * *$ & 9.861 \\
\hline Video & & & 0.648 & 0.032 & 0.899 & 0.059 \\
\hline Updates & & & 0.181 & 1.646 & 0.176 & 1.203 \\
\hline Comments & & & & & -0.020 & 0.002 \\
\hline $\mathrm{Fb} \_$page & & & & & -0.300 & 0.242 \\
\hline Tw_account & & & & & 0.125 & 0.121 \\
\hline SN_index & 3.969 & 0.114 & $28.259^{*}$ & 3.645 & $27.871 *$ & 3.522 \\
\hline Project Category Dummies & YES & & YES & & YES & \\
\hline Costant & 3.390 & 0.211 & -11.516 & 1.518 & -11.235 & 1.430 \\
\hline $\mathrm{N}^{\circ}$ of observations & 578 & & 578 & & 578 & \\
\hline Mean VIF & 1.360 & & 1.388 & & 1.384 & \\
\hline Maximum VIF & 2.322 & & 2.326 & & 2.334 & \\
\hline \multicolumn{7}{|l|}{ Model Summary } \\
\hline-2 Log likelihood & 238.816 & & 226.670 & & 226.335 & \\
\hline Cox \& Snell R-Square & 0.466 & & 0.482 & & 0.482 & \\
\hline Negelkerke R-Square & 0.656 & & 0.679 & & 0.680 & \\
\hline \multicolumn{7}{|l|}{ Hosmer and Lemeshow Test: } \\
\hline Chi-square & 12.285 & & 4.349 & & 5.357 & \\
\hline Sig. & 0.139 & & 0.824 & & 0.719 & \\
\hline
\end{tabular}

Significance level: ***1\%; **5\%;

In summary, early-late backers (H1) and the participation of a mentor (H2) are factors associated with an increase in the likelihood of a reward-based crowdfunding campaign succeeding. Thus, the results of the data analysis prove the hypotheses presented.

With respect to the control variables, in accordance with prior evidence (Colombo et al., 2014; Cordova et al., 2015; Mollick, 2014), the findings show that the probability of success is negatively associated with the capital target. If this result is interpreted through the theory of signals, one possible reason is that when funders are faced with relatively larger projects, they feel that their contribution is not as big determinant of success as it is for smaller ones. Therefore, they could decide to sustain projects that have a smaller funding target but seem to have more chances of success. The higher the funding requested, the lower is the probability of a project reaching the funding goal due to the generation of an adverse signal that reduces the conviction of the crowd to support a new initiative. Moreover, the second and the third models show that the insertion of photos and the social network index have a significant impact on the chances of success, but with a different sign. In fact, consistent with other empirical studies (Kunz et al., 2017), the present findings show that photos have a negative impact on the likelihood of a crowdfunding campaign succeeding, and that the higher the penetration index of social networks, the higher is the likelihood of a project reaching the funding goal. Probably, the recourse to photos, even if it is only theoretically a sign of quality (Mollick, 2014), does not necessarily mean that the project has greater appeal. Low image quality or a negative subjective evaluation of this kind of graphic material may contribute to undermining the attractiveness of a new initiative. At the same time, it is possible that excessive use of images will result in a very cluttered project page which could hinder readability, without necessarily adding useful information. On the contrary, given the virtual environment of crowdfunding, increasing the diffusion of confidence within digital social networks also increases the opportunity to leverage on additional media to lend popularity to a project among potential funder.

\section{Discussion}

Starting from two well-established conceptual frameworks - the information asymmetry theory (Akerlof, 1970) and the signalling theory (Spence, 1973) - this paper examines the themes related to the success of reward-based crowdfunding campaigns. Both theories present unique characteristics in the crowdfunding market that may be 
an obstacle to reaching the funding target, and this is confirmed by the wide gap that normally distinguishes successful campaigns from failed ones. Consistent with this issue, our analysis aimed to examine in depth the role of two kinds of backers that have not yet been investigated, and may contribute to the reliability and feasibility of a crowdfunding initiative. In particular, based on the concept of social information being embodied in others' funding decisions (Kuppuswamy \& Bayus, 2015) and assuming that the crowd is not a monolithic entity, the present study investigates the impact of backers that intervene at the beginning of the tail of the campaign and the effect of renowned firms that act as mentors of a new project. By segmenting the crowd according to entry time, the findings confirm that early-late backers have a positive impact on the likelihood of a project reaching its capital target. Moreover, by isolating renowned companies from backers who intervene in the funding process, the study shows that this new form of mentoring is a determinant of the success of crowdfunding campaigns.

The paper advances the body of knowledge in several aspects. First, the results identify new signals that have so far not been covered in the crowdfunding literature. In fact, early-late backers contribute to reinforce the deadline effect by focusing on backers who hesitate until the last days or hours of the fundraising window.

Second, the segregation of financial and knowledge capital, which typically characterizes the crowdfunding model, is mitigated by the intervention of companies that can be identified as more experienced backers. Unlike what happens in the lending-model of crowdfunding (Lin, Sias, \& Wei, 2015), backers are more likely to participate when an expert investor has already supported a crowdfunding campaign. This new type of mentor expresses more credible judgment about the reliability and feasibility of a project.

Third, our study examines in depth the functioning of reward-based crowdfunding in the Italian context, which is very little investigated and which still has technological and cultural limitations in comparison with other advanced countries such as the US and UK. As demonstrated by the impact of the social network index, the potential for success of the Italian crowdfunding market may increase by reduction of the digital divide that distinguishes Italy from other advanced contexts.

Fourth, since the framework of this study is rooted in the information asymmetry theory and in the theory of signals, the paper further contributes to these research streams by applying these theories in novel contexts and simultaneously providing additional insights into the crowdfunding theory. With regard to crowdfunding, the paper also contributes by updating existing findings on success factors in reward-based crowdfunding and providing additional insights about the behaviour of the crowd.

This study has some limitations that call for future research efforts. The paper attributes the positive relationship between the dynamics of backers and the success of campaigns to several constructs such as social information. Future works should take a step further in this direction by administering a survey among the backers of crowdfunding projects. In addition, the findings should be generalized very cautiously, since the study uses data from only one country. Therefore, through analysis of success determinants across different contexts, additional investigations could provide information about whether backer behaviour differs across cultural contexts.

Notwithstanding the mentioned limits, the paper has interesting implications for both the applicants of crowdfunding projects and the managers of internet platforms. The former should not only monitor the number of earlier advocates, but also make a constant effort to sustain the crowdfunding project along the entire fundraising cycle. In fact, given the critical role of backers at the tail of the campaign, the sense of success represented by early pledges should not lower the guard of the project creator, who must remain vigilant throughout the duration of the campaign. Moreover, both creators of projects and managers of crowdfunding platforms should acknowledge the importance of mentors. Platforms should be designed so as to reserve specific space and evidence for the participation of backers represented by renowned already operating organizations. Moreover, proponents should pay attention to the involvement of remarkable advocates who may act as a positive signal for the success of a campaign. All these factors may further improve capital allocation in a market such as reward-based crowdfunding, which is becoming more mature but is still limited by the presence of information asymmetry.

\section{References}

Agrawal, A., Catalini, C., \& Goldfarb, A. (2014). Some simple economics of crowdfunding. Innovation Policy and the Economy, 14(1), 63-97. https://doi.org/10.1086/674021

Agrawal, A., Catalini, C., \& Goldfarb, A. (2015). Crowdfunding: Geography, social networks, and the timing of investment decisions. Journal of Economics \& Management Strategy, 24(2), 253-274. https://doi.org/10.1111/jems.12093 
Ahlers, G. K., Cumming, D., Günther, C., \& Schweizer, D. (2015). Signaling in equity crowdfunding. Entrepreneurship Theory and Practice, 39(4), 955-980. https://doi.org/10.1111/etap.12157

Akerlof, G. A. (1970). The market for "lemons": quality uncertainty and the market mechanism. The Quarterly Journal of Economics, 84(3), 488-500. https://doi.org/10.2307/1879431

Ariely, D., \& Simonson, I. (2003). Buying, bidding, playing, or competing? Value assessment and decision dynamics in online auctions. Journal of Consumer Psychology, 13(1-2), 113-123. https://doi.org/10.1207/S15327663JCP13-1\&2_10

Ariely, D., \& Wertenbroch, K. (2002). Procrastination, deadlines, and performance: Self-control by precommitment. Psychological Science, 13(3), 219-224. https://doi.org/10.1111/1467-9280.00441

Ariely, D., Ockenfels, A., \& Roth, A. E. (2003). An experimental analysis of ending rules in internet auctions. The Rand Journal of Economics, 36(4), 891-908. https://doi.org/10.2139/ssrn.429963

Baum, J. A., \& Silverman, B. S. (2004). Picking winners or building them? Alliance, intellectual, and human capital as selection criteria in venture financing and performance of biotechnology startups. Journal of Business Venturing, 19(3), 411-436. https://doi.org/10.1016/S0883-9026(03)00038-7

Belleflamme, P., Lambert, T., \& Schwienbacher, A. (2014). Crowdfunding: tapping the right crowd. Journal of Business Venturing, 29(5), 585-609. https://doi.org/10.1016/j.jbusvent.2013.07.003

Bikhchandani, S., Hirshleifer, D., \& Welch, I. (1998). Learning from the behavior of others: Conformity, fads, and informational cascades. The Journal of Economic Perspectives, 12(3), 151-170. https://doi.org/10.1257/jep.12.3.151

Bouassis, K., Maque, I., \& Méric, J. (2016). A Cartography of the Academic Literature on Crowdfunding. In M. J., J. Brabet, \& I. Maque (Eds.), International Perspectives on Crowdfunding: Positive, Normative and Critical Theory (pp. xxi-xxxvi). Emerald Group Publishing Limited.

Colombo, M. G., Franzoni, C., \& Rossi - Lamastra, C. (2014). Internal social capital and the attraction of early contributions in crowdfunding. Entrepreneurship Theory and Practice, 39(1), 75-100. https://doi.org/10.1111/etap.12118

Cordova, A., Dolci, J., \& Gianfrate, G. (2015). The determinants of crowdfunding success: evidence from technology projects. Procedia-Social and Behavioral Sciences, 181, 115-124. https://doi.org/10.1016/j.sbspro.2015.04.872

Courtney, C., Dutta, S., \& Li, Y. (2017). Resolving information asymmetry: Signaling, endorsement, and crowdfunding success. Entrepreneurship Theory and Practice, 41(2), 265-290. https://doi.org/10.1111/etap.12267

Cumming, D. J., Leboeuf, G., \& Schwienbacher, A. (2014). Crowdfunding models: Keep-it-all vs. all-or-nothing. Paris December 2014 Finance Meeting EUROFIDAI-AFFI paper (Vol.10).

Frydrych, D., Bock, A. J., Kinder, T., \& Koeck, B. (2014). Exploring entrepreneurial legitimacy in reward-based crowdfunding. Venture Capital, 16(3), 247-269. https://doi.org/10.1080/13691066.2014.916512

Gneezy, U., Kapteyn, A., \& Potters, J. (2003). Evaluation periods and asset prices in a market experiment. The Journal of Finance, 58(2), 821-838. https://doi.org/10.1111/1540-6261.00547

Gompers, P. A. (1995). Optimal investment, monitoring, and the staging of venture capital. The Journal of Finance, 50(5), 1461-1489. https://doi.org/10.1111/j.1540-6261.1995.tb05185.x

Gompers, P. A. (1996). Grandstanding in the venture capital industry. Journal of Financial Economics, 42(1), 133-156. https://doi.org/10.1016/0304-405X(96)00874-4

Gompers, P. A., \& Lerner, J. (1997). Risk and reward in private equity investments: The challenge of performance assessment. The Journal of Private Equity, 1(2), 5-12. https://doi.org/10.3905/jpe.1997.409670

Greve, A., \& Salaff, J. W. (2003). Social networks and entrepreneurship. Entrepreneurship Theory and Practice, 28(1), 1-22. https://doi.org/10.1111/1540-8520.00029

Griffin, Z. J. (2012). Crowdfunding: fleecing the American masses. Case Western. Reserve Journal of Law, Technology \& the Internet, 4, 375. https://doi.org/10.2139/ssrn.2030001

Hu, M., Li, X., \& Shi, M. (2015). Product and pricing decisions in crowdfunding. Marketing Science, 34(3), 331-345. https://doi.org/10.1287/mksc.2014.0900 
Kaartemo, V. (2017). The Elements of a Successful Crowdfunding Campaign: A Systematic Literature Review of Crowdfunding Performance. International Review of Entrepreneurship, 15(3).

Kang, L., Jiang, Q., \& Tan, C. H. (2017). Remarkable advocates: An investigation of geographic distance and social capital for crowdfunding. Information \& Management, 54(3), 336-348. https://doi.org/10.1016/j.im.2016.09.001

Kim, K., \& Viswanathan, S. (2016). The 'Experts' in the Crowd: The Role of 'Expert' Investors in a Crowdfunding Market. Paper presented at TPRC 41: The 41st Research Conference on Communication, Information and Internet Policy. https://doi.org/10.2139/ssrn.2258243

Kunz, M. M., Bretschneider, U., Erler, M., \& Leimeister, J. M. (2017). An empirical investigation of signaling in reward-based crowdfunding. Electronic Commerce Research, 1-37. ISSN 1389-5753. https://doi.org/10.1007/s10660-016-9249-0

Kuppuswamy, V., \& Bayus, B. L. (2015). Crowdfunding creative ideas: the dynamics of project backers in kickstarter UNC Kenan-Flagler Research Paper No. 2013-15. https://doi.org/10.2139/ssrn.2234765

Kuppuswamy, V., \& Bayus, B. L. (2017). Does my contribution to your crowdfunding project matter? Journal of Business Venturing, 32(1), 72-89.

Lee, P. M., \& Wahal, S. (2004). Grandstanding, certification and the underpricing of venture capital backed IPOs. Journal of Financial Economics, 73(2), 375-407. https://doi.org/10.1016/j.jfineco.2003.09.003

Lin, M., Sias, R., \& Wei, Z. (2015). “Smart Money”: Institutional Investors in Online Crowdfunding. Working Paper.

Massolution. (2015). 2015CF The Crowdfunding Industry Report. Retrieved from http://reports.crowdsourcing.org

McDonald, J. F., \& Moffitt, R. A. (1980). The uses of Tobit analysis. The Review of Economics and Statistics, 63(2), 318-321. https://doi.org/10.2307/1924766

Megginson, W. L., \& Weiss. A. K. (1991). Venture capitalist certification in initial public offerings. The Journal of Finance, 46(3), 879-903. https://doi.org/10.1111/j.1540-6261.1991.tb03770.x

Mollick, E. R. (2014). The dynamics of crowdfunding: an exploratory study. Journal of Business Venturing, 29(1), 1-16. https://doi.org/10.1016/j.jbusvent.2013.06.005

Nahapiet, J., \& Ghoshal, S. (1998). Social capital, intellectual capital, and the organizational advantage. Academy of Management Review, 23(2), 242-266.

Ockenfels, A., \& Roth, A. E. (2006). Late and multiple bidding in second price Internet auctions: Theory and evidence concerning different rules for ending an auction. Games and Economic Behavior, 55(2), 297-320. https://doi.org/10.1016/j.geb.2005.02.010

Petersen, M. A. (2004). Information: Hard and soft (Working paper, Northwestern University). Retrieved from http://www.kellogg.northwestern.edu/faculty/petersen/htm/papers/softhard.pdf.

Ratner, B. (2009). The correlation coefficient: Its values range between $+1 /-1$, or do they? Journal of Targeting, Measurement and Analysis for Marketing, 17(2), 139-142. https://doi.org/10.1057/jt.2009.5

Roth, A. E., Murnighan, J. K., \& Schoumaker, F. (1988). The deadline effect in bargaining: Some experimental evidence. The American Economic Review, 78(4), 806-823.

Spence, M. (1973). Job Market Signaling. The Quarterly Journal of Economics, 87(3), 355-374. https://doi.org/10.2307/1882010

Starteed. (May 2016). Il crowdfunding in Italia: tutti I numeri e le piattaforme. Retrieved from https://blog.starteed.com/article?idA=2603272528428-348\#il-crowdfunding-in-italia:-tutti-i-numeri-e-le-pia ttaforme-(aggiornato-a-gennaio-2017)\&.

Stein, J. C. (2002). Information production and capital allocation: Decentralized versus hierarchical firms. The Journal of Finance, 57(5), 1891-1921. https://doi.org/10.1111/0022-1082.00483

Stuart, T. E., Ha, H., \& Ralph, C. H. (1999). Interorganizational endorsements and the performance of entrepreneurial ventures. Administrative Science Quarterly, 44(2), 315-349. https://doi.org/10.2307/2666998

Thies, F., \& Wessel, M. (2014). The Circular Effects of Popularity Information and Electronic Word-of-Mouth on 
Consumer Decision-Making: Evidence from a Crowdfunding Platform. Paper presented at the European Conference on Information Systems, Tel Aviv, Israel.

Tomboc, G. F. B. (2013). The Lemons Problem in Crowdfunding. The John Marshall Journal of Information Technology and Privacy Law, 30, 253.

Università Cattolica, TIM. (2016). Il Crowdfunding in Italia. Report 2016. Retrieved from http://crowdfundingreport.telecomitalia.com/

We are social. (2016). Digital, Social \& Mobile in 2015 - We are social's compendium of global digital statistics.

Retrieved from http://www.slideshare.net/wearesocialsg/digital-social-mobile-in-2015

\section{Notes}

Note 1. The investors in a project presented on a crowdfunding platform are called 'funders' (Mollick, 2014), 'advocates' (Kang \& Jiang, 2017) or 'backers' (Colombo et al., 2014). Therefore, the paper uses these terms synonymously.

Note 2. The act of financing a campaign can be divided into a number of time-consuming phases (Colombo et al., 2014): registration on the platform, understanding of the financial terms of the project, activation of the on-line payment method. The money is parked in an escrow account until the campaign is over and its outcome is known.

Note 3. The time fraction equal to one-sixth of a given interval was adopted by Colombo et al. (2014) in their study on early-backers.

Note 4. The projects are classified into the following sectors: Theatre, Publishing, Cinema, Music, Civic, Food, Outdoor, Games and Tech. In order to avoid the 'dummy trap', the logistic regressions include eight dummies out of nine.

Note 5. Data not reported, correlation matrix and variance inflation factors (VIF) are available upon request from the authors.

\section{Appendix A}

Content analysis: A comparison between US and Italian platforms

\begin{tabular}{lcccc}
\hline Information & \multicolumn{2}{c}{ Platforms } & \\
\hline Campaign page & Indiegogo & Kickstarter & Eppela & Produzioni dal basso \\
Funding requested & Yes & Yes & Yes & Yes \\
Funding achieved & Yes & Yes & Yes & Yes \\
Days to go & Yes & Yes & Yes & Yes \\
Video/Photo & Yes & Yes & Yes & Yes \\
Project Description & Yes & Yes & Yes & Yes \\
Number of backers & Yes & Yes & Yes & Yes \\
Number of rewards & Yes & Yes & Yes & Yes \\
Updates/Comments & Yes & Yes & Yes & Yes \\
Linked Websites & Yes & Yes & Yes & Produzioni dal basso \\
Proponents & Indiegogo & Kickstarter & Eppela & No \\
Biography & Yes & Yes & No & No \\
Identity verification & Yes & Yes & No & No \\
Backed/Created projects & Yes & Yes & No & Po \\
Facebook friends & Yes & Yes & Eppela & Produzioni dal basso \\
Backers & Indiegogo & Kickstarter & No & No \\
Biography & Yes & Yes & No & No \\
Identity verification & Yes & Yes & No & No \\
Backed/Created projects & Yes & Yes & No & No \\
Amount financed & Yes & Yes & & \\
\hline
\end{tabular}

\section{Copyrights}

Copyright for this article is retained by the author(s), with first publication rights granted to the journal.

This is an open-access article distributed under the terms and conditions of the Creative Commons Attribution license (http://creativecommons.org/licenses/by/4.0/). 